\title{
Genetic Variation of the Pathogen Causing Impatiens Downy Mildew Predating and Including Twenty-first Century Epidemics on Impatiens walleriana
}

Catalina Salgado-Salazar, U.S. Department of Agriculture, Agricultural Research Service (USDA-ARS), Mycology and Nematology Genetic Diversity and Biology Laboratory, Beltsville, MD 20705; Oak Ridge Institute for Science and Education, ARS Research Participation Program, MC-100-44, Oak Ridge, TN 37831; and Department of Plant Biology, Rutgers University, New Brunswick, NJ 08901; Nicholas LeBlanc, USDA-ARS, Mycology and Nematology Genetic Diversity and Biology Laboratory, Beltsville, MD 20705; and Oak Ridge Institute for Science and Education, ARS Research Participation Program, MC-100-44, Oak Ridge, TN 37831; Adnan Ismaiel, USDA-ARS, Mycology and Nematology Genetic Diversity and Biology Laboratory, Beltsville, MD 20705; Yazmín Rivera, USDA-ARS, Mycology and Nematology Genetic Diversity and Biology Laboratory, Beltsville, MD 20705; and Department of Plant Biology, Rutgers University, New Brunswick, NJ 08901; Colleen Y. Warfield, Ball Horticultural Company, West Chicago, IL 60185; and Jo Anne Crouch, ${ }^{\dagger}$ USDA-ARS, Mycology and Nematology Genetic Diversity and Biology Laboratory, Beltsville, MD 20705

\begin{abstract}
Impatiens downy mildew (IDM) of cultivated Impatiens walleriana has had a significant economic impact on the ornamental horticulture industry in the United States and globally. Although recent IDM outbreaks started in 2003, downy mildews on noncultivated Impatiens species have been documented since the 1880s. To understand the relationship between the pathogen causing recent epidemics and the pathogen historically present in the United States, this work characterized genetic variation among a collection of 1,000 samples on 18 plant hosts. Samples included collections during recent IDM epidemics and historical herbarium specimens. Ten major genotypes were identified from cloned rDNA amplicon sequencing and

endpoint SNP genotyping. Three genotypes accounted for $>95 \%$ of the samples, with only one of these three genotypes found on samples predating recent IDM outbreaks. Based on phylogenetic analysis integrating data from three markers and the presence of individual genotypes on multiple Impatiens species, there was some evidence of pathogen-specific infection of I. noli-tangere, but the distinction between genotypes infecting I. walleriana and I. balsamina was not upheld. Overall, this work provides evidence that the majority of rDNA genotypes recovered from recent IDM epidemics are different from historical U.S. genotypes, and that these genotypes can infect Impatiens spp. other than I. walleriana.
\end{abstract}

During the past decade, downy mildew diseases caused by oomycete pathogens in the Peronosporaceae have emerged as some of the most destructive diseases of specialty crops in the United States and worldwide (Thines and Choi 2016). Notable examples of specialty crops recently affected by downy mildew diseases include hyssop (Agastache foeniculum), basil (Ocimum basilicum), coleus (Plectranthus scutellarioides), cucumber (Cucumis sativus), rudbeckia (Rudbeckia fulgida), and garden impatiens (Impatiens walleriana) (Cohen et al. 2015; Rivera et al. 2016a,b,c; Thines and Choi 2016; Thines et al. 2009). Among

Current address of Y. Rivera: USDA-APHIS-PPQ, Center for Plant Health Science and Technology, BARC-East, Beltsville, MD 20705.

${ }^{\dagger}$ Corresponding author: J. A. Crouch; E-mail: joanne.crouch@ars.usda.gov

C. Salgado-Salazar and N. LeBlanc contributed equally to this study. Mention of trade names or commercial products in this publication is solely for the purpose of providing specific information and does not imply recommendation or endorsement by the USDA. The USDA is an equal opportunity provider and employer.

Funding: This work was supported by funds from the 2013-2014 USDAAPHIS Farm Bill 10201, USDA-ARS project 8042-22000-298-00-D, and by the appointments of C. Salgado-Salazar and N. LeBlanc to the ARS Research Participation Program administered by the Oak Ridge Institute for Science and Education (ORISE) through an interagency agreement between the U.S. Department of Energy (DOE) and the USDA. ORISE is managed by ORAU under DOE contract number DE-AC05-06OR23100.

*The $\boldsymbol{e}$-Xtra logo stands for "electronic extra" and indicates that three supplementary tables and two supplementary figures are published online.

Accepted for publication 7 May 2018.

C 2018 The American Phytopathological Society nonedible specialty crops, no plant has been impacted more by downy mildew than I. walleriana, a floriferous, shade-tolerant flowering annual used extensively in display gardens and landscape beds, container gardens and hanging baskets. Since the early twenty-first century, destructive outbreaks of impatiens downy mildew (IDM) have been documented from I. walleriana in the U.K., continental Europe, Australia, Japan, Korea, and Taiwan (Bulajić et al. 2011; Choi et al. 2009; Cunnington et al. 2008; Kirschner 2013; Lane et al. 2005; Petróczy et al. 2012; Satou et al. 2013; Shen et al. 2013; Toppe et al. 2010; Vajna 2011). In the United States, sporadic outbreaks of IDM were first reported from I. walleriana in commercial greenhouses in Tennessee and California in 2004 (Wegulo et al. 2004), North Carolina in 2007 (C. Warfield, personal communication) and from New York landscapes in 2009 (M. Daughtrey, personal communication). However, it was not until the 2011 and 2012 growing seasons that IDM became widespread in landscape plantings across the continental United States and the Hawaiian Islands (Baysal-Gurel et al. 2012; Conner et al. 2014; Crouch et al. 2014; McGinnis et al. 2015; Palmateer et al. 2013; Ward et al. 2013; Warfield 2012). Symptoms of downy mildew are especially severe on I. walleriana and include leaf yellowing, flower drop, complete defoliation, stem rot, and eventual plant death (Hansen et al. 2013; Shen et al. 2013). Losses due to IDM can be staggering, with 80 to $100 \%$ disease incidence widely reported (Baysal-Gurel et al. 2012; Bulajić et al. 2011; Choi et al. 2009; Cunnington et al. 2008; Kirschner 2013; Lane et al. 2005; Palmateer et al. 2013; Petróczy et al. 2012; Shen et al. 2013; Vajna 2011; Wegulo et al. 2004). Since the onset of IDM affecting I. walleriana in the United States, conservative estimates indicate that the value of this important ornamental bedding crop has decreased by $\$ 72$ million annually, or approximately $40 \%$ of the annual wholesale value (USDA-National Agricultural Statistics Service Census of Agriculture 1998 and 2014 reports, https://www.agcensus.usda.gov).

Impatiens downy mildew is not a new disease. In fact, the first samples of this disease were collected in Germany in the late 1870s 
and were used to describe the causal pathogen Plasmopara obducens from the cotyledons of I. noli-tangere (Schröeter 1877). P. obducens was subsequently documented in the United States during the 1880 s (Farr and Rossman 2018). Despite the historical presence of IDM, the twenty-first century IDM outbreaks are unique in that they mark the first time commercial cultivars of I. walleriana have been impacted by this disease since their introduction to the ornamental industry in the late 1960s. Prior to the twenty-first century, P. obducens was only known from five species of Impatiens: I. balsamina, I. capensis, I. pallida, I. noli-tangere, and I. textori (Farr and Rossman 2018). With the exception of I. balsamina, which has been grown for centuries as a medicinal plant, these four Impatiens species are rarely cultivated in the horticultural trade (Morgan 2007). Of the approximately 1,000 known species of Impatiens, most live in the wild, commonly as understory woodland plants (Morgan 2007; Yu et al. 2016). The effect of downy mildew on the health of Impatiens species other than I. walleriana is largely unknown. Outside of the current IDM outbreaks affecting I. walleriana, disease symptoms are rarely documented from Impatiens host plants infected with the pathogen (but see Choi et al. 2009; Tanner et al. 2008). New Guinea impatiens hybrids (I. hawkeri) are another commercially grown Impatiens that are generally not susceptible to the disease (Hansen et al. 2013), although infection by the pathogen can be induced (C. Warfield, personal communication). Even the original record of $P$. obducens made from wild-grown I. noli-tangere in Germany describes the infected plants in good health, with the only external signs of infection occurring as dense mycelial growth on the underside of cotyledons (Schröeter 1877). Literature dealing with IDM prior to its association with cultivated $I$. walleriana focuses primarily on the organism from a morphological and taxonomic standpoint, or as a component of higher-level taxonomic assessments, rather than as a plant pathogen (e.g., Görg et al. 2017; McTaggart et al. 2015; Thines and Choi 2016; Thines et al. 2007; Voglmayr and Thines 2007; Voglmayr et al. 2004). Very little is known about the biology of the causal pathogen of IDM.

The recent emergence of downy mildew as a destructive disease of cultivated I. walleriana raises a basic question: is the causal agent of the twenty-first century IDM outbreaks fundamentally the same organism that was documented from wild-grown species of Impatiens throughout most of the nineteenth and twentieth centuries? A recent phylogenetic study described the downy mildew pathogens on $I$. walleriana and I. balsamina as two novel, host-specific species of Plasmopara, distinct from $P$. obducens on $I$. noli-tangere, namely $P$. destructor and $P$. velutina, respectively (Görg et al. 2017). This description of novel host-specific downy mildew species on Impatiens is in general agreement with the high levels of host specialization documented among oomycetes that cause downy mildew (Choi and Thines 2015; Choi et al. 2015; Göker et al. 2007; Rivera et al. 2016c; Rouxel et al. 2013, 2014; Runge et al. 2011; Thines and Choi 2016). However, the recent taxonomic proposal for Plasmopara associated with Impatiens used a small number of samples $(n=12)$, did not include the $P$. obducens type materials, and did not use any IDM samples collected prior to 2004 (Görg et al. 2017). Significant differences in morphological characteristics (i.e., sporangia, sporangiophores, ultimate branchlets) were found among the Plasmopara specimens from three Impatiens species (Görg et al. 2017). However, morphological characteristics of downy mildews may be influenced by infection of different plant hosts (Runge and Thines 2011), and the observed differences may simply be due to the isolation of the Plasmopara from the different Impatiens species, or environment-induced plasticity, especially given the wide overlapping range of measurements reported. In addition, although three markers were sequenced, the sole nuclear marker showed only two variant sites and the two mitochondrial markers overlapped within the same gene, meaning that the analysis was not a reflection of genetic variation across multiple loci. Considering these factors, it is still unclear if the pathogen responsible for recent outbreaks of IDM is genetically divergent from those identified as $P$. obducens and those historically present on Impatiens.

In this study, we broadly address the identity of the causal agent of IDM affecting cultivated I. walleriana in the twenty-first century in the United States using genotypic and phylogenetic methods. By including disease samples from historical herbarium specimens and modern samples, it was possible to test for potential genetic differentiation of the causal pathogen of the twenty-first century IDM outbreaks. In addition, by analyzing samples from multiple species of Impatiens, this work tested the hypothesis that genetic divergence among downy mildews on these plants is associated with host specificity. Overall, this work provides the first survey of genetic variation of the causal pathogen of IDM across populations in the United States and provides a foundation for future research into the evolution of the pathogen and control of the disease.

\section{Materials and Methods}

Sample collections. A total of 1,000 downy mildew samples were included in this study. An overview of the samples is provided in Table 1, and detailed listings are provided in Supplementary Tables S1 and S2. The collection included 984 samples of Plasmopara obducens sensu lato (i.e., not discriminating the species associated with I. balsamina and I. walleriana recently described by Görg et al. 2017). To simplify discussion, these $P$. obducens s.l. samples will be hereafter referred to as $P$. obducens. Sixteen samples from three closely related

Table 1. Summary of SNP and rDNA genotypes among 1,000 downy mildew samples taken from Impatiens and other hosts. Unless otherwise noted, all samples are Plasmopara obducens sensu lato.

\begin{tabular}{|c|c|c|c|c|c|c|}
\hline Sample type & Locations & Origin & $\begin{array}{c}\text { Total } \\
\text { samples }\end{array}$ & $\begin{array}{l}\text { Collection } \\
\text { date(s) }\end{array}$ & rDNA/SNP genotype(s) & Host substrate(s) \\
\hline $\begin{array}{l}\text { U.S. samples, fresh collections } \\
\text { (post-epidemics) }\end{array}$ & 161 & 30 states & 895 & 2011-2014 & G1, G2, G3, G4, G7, G8, G9, G10, C & $\begin{array}{l}\text { Impatiens arguta, } \\
\text { I. auricoma, I. balsamina, } \\
\text { I. sp. 'Blue Angel', } \\
\text { I. capensis, I. flanaganiae, } \\
\text { I. hochstetteri, I. omeiana, } \\
\text { I. walleriana }\end{array}$ \\
\hline $\begin{array}{l}\text { U.S. samples, herbarium specimens } \\
\text { (first U.S. specimen on } \\
\text { I. walleriana) }\end{array}$ & 1 & Tennessee & 2 & 2004 & G5, G6 & I. walleriana \\
\hline $\begin{array}{l}\text { U.S. samples, historical herbarium } \\
\text { specimens (pre-epidemics) }\end{array}$ & 54 & 18 states & 55 & 1881-1942 & $\mathrm{G} 3, \mathrm{G} 4, \mathrm{~B}, \mathrm{C}$ & $\begin{array}{l}\text { I. biflora, I. fulva, } \\
\text { I. pallida, Impatiens sp. }\end{array}$ \\
\hline $\begin{array}{l}\text { Non-U.S. samples, fresh } \\
\text { collections (post-epidemics) }\end{array}$ & 18 & 8 countries & 18 & $2007-2013$ & $\mathrm{G} 1, \mathrm{G} 2, \mathrm{G} 3$ & I. walleriana \\
\hline $\begin{array}{l}\text { Non-U.S. samples, herbarium } \\
\text { specimens (pre- and } \\
\text { post-epidemics) }\end{array}$ & 17 & 7 countries & 17 & $1877-2005$ & G3 & $\begin{array}{l}\text { I. aurea, I. noli-tangere, } \\
\text { I. textori, Impatiens sp. }\end{array}$ \\
\hline $\begin{array}{l}\text { Outgroup samples (Bremiella } \\
\text { megasperma, Plasmopara } \\
\text { constantinescui, Peronospora } \\
\text { alsinearum) }\end{array}$ & 16 & $\begin{array}{l}\text { U.S. and } \\
\text { Canada }\end{array}$ & 16 & $1880 s-1943$ & $1,3,7,8, \mathrm{~B}, \mathrm{C}, \mathrm{H}, \mathrm{I}, \mathrm{K}$ & $\begin{array}{l}\text { I. biflora, I. fulva, I. } \\
\text { pallida, Viola tenella, } \\
\text { V. tricolor var. arvensis }\end{array}$ \\
\hline
\end{tabular}


species, P. constantinescui, Bremiella megasperma, and Peronospora alsinearum, were included for outgroup comparisons. Samples originated from two primary sources: (i) fresh collections of detached leaves from diseased plant material; and (ii) herbarium specimens from the U.S. National Fungus Collections (BPI; USDA-ARS, Beltsville, MD). Fresh collections were made in the United States from 895 foliar samples of Impatiens spp. exhibiting signs of $P$. obducens or symptoms of IDM, representing 161 different geographic locations. With the exception of 47 samples, all fresh collections were made from naturally infected plants. The remaining 47 freshly collected samples, provided by Margery Daughrety (Cornell University), correspond to eight species of Impatiens plants (I. arguta, I. auricoma, I. balsamina, I. capensis, I. flanaganiae, I. hochstetteri, I. omeiana, and I. sp. 'Blue Angel') inoculated with spores originally collected from infected I. walleriana plants. To test for the presence of different $P$. obducens genotypes on individual plants within sites, multiple leaves/plants were processed independently when adequate material was available. Fifty-five U.S. herbarium samples, including $P$. obducens infecting species of noncultivated Impatiens and two samples from the first outbreak on I. walleriana in 2004, were included to compare pre-epidemic or historical samples to those collected after the first major U.S. IDM outbreak in 2004. A total of 35 P. obducens samples collected from outside the United States were also included in the study, comprising 18 fresh samples of IDM on I. walleriana and 17 samples from herbarium specimens of IDM on Impatiens spp. other than I. walleriana (Table 1).

All freshly collected samples were exposed to ambient temperatures during the collection process, which included time spent with collectors, time spent in transit to our lab either by hand delivery or via commercial shipping providers, and time spent in storage in our lab in a double-walled metal herbarium cabinet at room temperature (ca. $25^{\circ} \mathrm{C}$ ) prior to DNA extraction (one day to one month). Long-term conditions experienced by the herbarium specimens are unknowable and may have included any number of variables (Verkley et al. 2015), but at the time of sampling, the specimens were stored within acid-free paper envelopes in double-walled metal herbarium cabinets at ambient temperature, approximately $16-18^{\circ} \mathrm{C}$.

Extraction of DNA from IDM samples. Extraction of total DNA for the majority of leaf samples was performed by excising and chopping ca. $10 \mathrm{~mm}^{2}$ leaf sections colonized by $P$. obducens using a sterile razor blade. For samples collected from Michigan, sporangia and sporangiospores stored in microcentrifuge tubes were provided courtesy of Mary Hausbeck (Michigan State University), from material originally harvested from the surface of infected $I$. walleriana leaf tissue. Samples were homogenized in $2.0 \mathrm{ml}$ microcentrifuge tubes using $0.5 \mathrm{~mm}$ sterile glass beads (Cell Disruption Media; Scientific Industries, Inc., Bohemia, NY) in a FastPrep 24 instrument (MP Biomedicals, Santa Ana, CA) for two cycles of $20 \mathrm{~s}$ in the presence of $600 \mu \mathrm{l}$ Lysis Buffer AP1 (QIAGEN, Inc., Gaithersburg, MD). DNA was extracted in a QIAcube (QIAGEN) instrument using the DNeasy Plant Mini Kit (QIAGEN) according to manufacturer's instructions and then quantified using a NanoDrop 1000 spectrophotometer (Thermo Fisher Scientific, Inc., Wilmington, DE).
Ribosomal DNA PCR amplification, cloning, and sequencing. PCR amplification of an approximate $1,100 \mathrm{bp}$ segment of the partial 18S, ITS1, 5.8S, and partial ITS2 region of the rDNA was performed using forward primer DC6 (Bonants et al. 1997) and a new reverse primer designed for this study, Plob3 (5'-TTAGAAGACCAAG CAACTCG-3'). PCR amplifications were performed in a $25 \mu$ l total volume reaction containing $2.5 \mu 1$ 10x PCR buffer (New England Biolabs, Ipswich, MA), with $\mathrm{MgCl}_{2}$ at a final concentration of $1.5 \mathrm{mM}$, $0.2 \mathrm{mM}$ dNTPs, $0.2 \mu \mathrm{M}$ forward and reverse primers, $1.25 \mathrm{U}$ standard Taq DNA Polymerase (New England Biolabs), and $2.5 \mu \mathrm{l}$ of $1 / 10 \times$ concentration of the genomic DNA stock. Thermal cycling was performed by $5 \mathrm{~min}$ denaturation at $95^{\circ} \mathrm{C}$; followed by 40 cycles of $45 \mathrm{~s}$ at $95^{\circ} \mathrm{C}, 30 \mathrm{~s}$ at $55^{\circ} \mathrm{C}, 30 \mathrm{~s}$ at $72^{\circ} \mathrm{C}$. A final extension was performed for $10 \mathrm{~min}$ at $72^{\circ} \mathrm{C}$.

Amplicons from DC6/Plob3 amplification were sequenced to a minimum of 2 to $5 \times$ coverage using Sanger technology, either directly from amplicons or from plasmid preps after cloning of the amplicon. Direct sequences were primed for cycle sequencing using the DC6/Plob3 PCR primers and three custom designed internal sequencing primers PlasmoR2, PlasmoF1, and PlasmoR1 (5'-TGATG TACGGACACTGAT-3', 5'-CTTTCCACGTGAACCGTTTCA-3', and 5'-CCTTGTTACGACTTCACCTTC-3', respectively). Cloned templates were generated by ligating DC6/Plob3 amplicon into the pGEM-T Easy vector (Promega, Madison, WI). The resultant plasmids were transformed into $\alpha$-Select Gold Efficiency competent cells (BioLine, Taunton, MA), purified with the NucleoSpin Plasmid purification kit (Macherey-Nagel, Duren, Germany), and sequenced from the SP6 and T7 primer sites located on the vector and the three internal sequencing primers. Sequencing was performed using the BigDye Terminator 3.1 cycle sequencing kit (Applied Biosystems, Foster City, CA) on an Applied Biosystems 3130xl Genetic Analyzer (Applied Biosystems). Sequences were assembled using Sequencher 4.1 software (Gene Codes Corp., Madison, WI). Unique sequences were identified using DNAcollapser (http://users-birc.au.dk/biopv/ php/fabox/dnacollapser.php\#) to generate a reduced dataset, which was aligned using the ClustalX algorithm implemented in CLC Main Workbench v.6.8.1, with ends of the alignment trimmed so that all sequences were equal length. The alignment was used to construct a median joining network in SplitsTree v.4.12.3 (Huson and Bryant 2006).

Endpoint SNP genotyping. To develop custom TaqMan 5'nuclease endpoint assays to genotype $P$. obducens samples, four single nucleotide polymorphisms (SNPs) were identified from the rDNA nucleotide sequence alignment (Table 2). The assays were developed by first identifying seven SNPs across the rDNA sequence alignment that were diagnostic for G1, G2, or G3 rDNA groups (identified from cloned rDNA amplicon sequences), and then selecting the minimal number of SNPs that provided the unique genotype sufficient to characterize the rDNA group. At each of the SNP sites, only two alleles were observed from the sequence dataset. Primers and minor groove binding probe pairs were selected using the Custom TaqMan Assay Design Tool (Life Technologies, Carlsbad, CA), with the hydrolysis probe pairs labeled with either $5^{\prime}$-FAM or 5'-VIC fluorophores. All

Table 2. Endpoint SNP genotyping assay primers and probes

\begin{tabular}{lccclcl}
\hline $\begin{array}{l}\text { Assay } \\
\text { name }\end{array}$ & SNPa & $\begin{array}{c}\text { Amplicon } \\
\text { size (bp) }\end{array}$ & Forward (F) and reverse (R) primers (5' to 3') & Reporter 1 probe sequence $^{\mathbf{b}}$ & Reporter 2 probe sequence $^{\mathbf{c}}$ \\
\hline IDM134 & A/G & 67 & $\begin{array}{c}\text { F-TGCGTTCAACGAGTATACAACCTT } \\
\text { R-CTAGCACGATGCGCATTCAC }\end{array}$ & AAGATTACCCAGATCTATCG & ATTACCCAGACCTATCG \\
IDM498 & A/G & 101 & $\begin{array}{c}\text { F-CGTGAACCGTTCACCAAATAGT } \\
\text { R-CCACTTCACTATGATAGGACTCGTCTA }\end{array}$ & CAGCTGCTAACTTTAA & AGCTGCTGACTTTAA \\
IDM604 & A/T & 104 & $\begin{array}{c}\text { F-GGACATTATAGTCCGAGCTAGTAGCTA } \\
\text { R-GCTGAAAGTTGCTATCTAGTTAAAGCA }\end{array}$ & TCCCCACAGTATAATCAGTA & TCCCCACAGTATATTCAGTA \\
IDM1020 & A/T & 80 & $\begin{array}{c}\text { F-CGGCGACCAGTTTGTTTGC } \\
\text { R-GCGCATTGTTAGCCGAAACTAAC }\end{array}$ & ACCGCAAATAAAATAC & ACCGCAAATTAAATAC \\
\hline
\end{tabular}

\footnotetext{
a Nucleotides present at SNP identified based on sequencing cloned rDNA amplicons from Plasmopara obducens.

${ }^{\mathrm{b}}$ Reporter probe labeled at the $5^{\prime}$ end with 6-carboxyfluorescein (FAM) and labeled at the 3' end with a nonfluorescent quencher (NFQ). Diagnostic single nucleotide polymorphisms (SNPs) within probe sequences are identified in bold. Note all probe sequences, except assay IDM498, are listed in reverse orientation (i.e., $3^{\prime}$ to $5^{\prime}$ ) relative to the primers.

${ }^{\mathrm{c}}$ Reporter 2 probes were labeled at the $5^{\prime}$ end with the VIC fluorophore and labeled at the $3^{\prime}$ end with NFQ. Diagnostic SNPs within probe sequences are identified in bold. Note all probe sequences, except assay IDM498, are listed in reverse orientation (i.e., $3^{\prime}$ to $5^{\prime}$ ) relative to the primers.
} 
probes were labeled with a $3^{\prime}$ nonfluorescent quencher attached to a minor groove-binding moiety. Polymerase chain reaction amplifications were performed in white half-skirted 96-well LightCycler 480 Multiwell plates sealed with clear adhesive film (Roche Diagnostics, Indianapolis, IN) on the Roche LightCycler II 480 instrument (Roche Diagnostics). Negative controls (nuclease-free water) and positive controls (samples of known genotype, as determined through Sanger sequencing) were included on all plates. All samples were analyzed at least twice, and two or more biological replicates were included from 64 of the sample sites. Thermal cycling was performed in total volume of $10 \mu \mathrm{l}$ containing $5 \mu \mathrm{l}$ of $2 \times$ LightCycler 480 Probes Master Mix (Roche Diagnostics), $0.5 \mu \mathrm{l}$ of 20X SNP genotyping assay, $3.25 \mu \mathrm{l}$ of PCR grade water and $1.25 \mu 1$ of template DNA. Cycling was performed as follows: preincubation at $50^{\circ} \mathrm{C}$ for $2 \mathrm{~min}$, followed by initial denaturation for $15 \mathrm{~s}$ at $95^{\circ} \mathrm{C}$, with 35 subsequent cycles of amplification (denaturation at $95^{\circ} \mathrm{C}$ for $15 \mathrm{~s}$, annealing/extension at $61^{\circ} \mathrm{C}$ for 20 $\mathrm{s}$, and extension at $72^{\circ} \mathrm{C}$ for $1 \mathrm{~s}$ ). Fluorescence signals were collected during the annealing step using the dual color hydrolysis probe detection format in the Light Cycler 480 SW1.5 software. Data were analyzed using the endpoint genotypic analysis algorithm, with alleles called relative to the sequenced positive control samples. Positive assay results for allelic discrimination of the samples were determined when the endpoint scattergrams showed clearly separated clusters that were distinct from negative controls. Endpoint SNP genotypes were analyzed by scoring each of the four markers as homozygous (1, 1 or 2,2), or heterozygous $(1,2)$ and combining the data into genotypes using GenAlEx v. 6.501 (Peakall and Smouse 2012). A genotype network was constructed from the four rDNA SNPs using the median joining option in Network software v.4.612 (www.fluxus-engineering. com; Bandelt et al. 1999).

Phylogenetic analysis. Nine downy mildew samples from I. walleriana, I. balsamina, and I. noli-tangere were selected for phylogenetic analysis. Sequence data were generated from the three molecular marker regions used by Görg et al. (2017), namely cox2, cox2-1 spacer, and ITS. The ITS region was amplified using the DC6 and Plob3 primers from all twenty-first century samples (collected after 2004). Three samples from historical (collected prior to 1950) herbarium specimens failed to produce the approximate 1,000 bp amplicon using the DC6/Plob3 primers, which was a consistent result given known levels of degradation experienced by DNA in old samples (Verkley et al. 2015). Instead, the three known variant sites within the ITS region sequenced by Görg et al. (2017) were amplified using primers from the IDM498 and IDM604 genotyping assays, each producing approximately $100 \mathrm{bp}$ fragments (Table 2). Two markers were amplified from the mtDNA for all nine samples. First, an approximate 300 bp portion of the mitochondrial cytochrome oxidase subunit 2 ( $\operatorname{cox} 2$ ) gene was amplified using the CoxFn (Hudspeth et al. 2000) and CoxRc4 (Choi et al. 2015) primers. Second, a region downstream of $\operatorname{cox} 2$ ( $\operatorname{cox} 2-1$ spacer) was amplified using forward (5'-GGTCAATGTAGTGAGATCTGTG-3') and reverse (5'-GTTGAGAAAAGCCAACGAGTTGAC-3') primers, which were modified from those used in Görg et al. (2017) to account for poor amplification of the herbarium specimens.

PCR amplifications were performed using $25 \mu \mathrm{l}$ reactions containing 12.5 $\mu$ l MangoMix (Bioline, Taunton, MA, USA), $2 \mu \mathrm{l}$ of each primer $(10 \mu \mathrm{M}), 1 \mu \mathrm{l} \mathrm{MgCl} 2(50 \mathrm{mM}), 5.5 \mu \mathrm{l}$ PCR-grade water, and $2 \mu \mathrm{l}$ template DNA. Thermal cycling was performed by 5 min denaturation at $95^{\circ} \mathrm{C}$, followed by 30 cycles of $1 \mathrm{~min}$ at $95^{\circ} \mathrm{C}, 1 \mathrm{~min}$ at annealing temperature, $1 \mathrm{~min}$ at $72^{\circ} \mathrm{C}$. A final extension was performed for $10 \mathrm{~min}$ at $72^{\circ} \mathrm{C}$. All reactions used an annealing temperature of $55^{\circ} \mathrm{C}$ except the $\operatorname{cox} 2-1$ spacer, which used an annealing temperature of $52^{\circ} \mathrm{C}$. Cox 2 and $\cos 2-1$ spacer amplicons were directly sequenced using the forward and reverse primers used in the initial PCR reaction. To account for heterozygosity in the region, the ITS amplicons were cloned using the TOPO TA cloning kit with the pCR 2.1-TOPO vector (Life Technologies, Carlsbad, CA) and One Shot TOP10 Chemically Competent cells following manufacturer's instructions. Cloned ITS amplicons were sequenced from plasmid DNA using the M13-F and M13-R primers. Sequencing was performed using the BigDye Terminator 3.1 cycle sequencing kit (Applied Biosystems, Foster City, CA) as described in previous sections.

Chromatograms were processed and sequences were assembled into contigs using Geneious v10.2.3 (Kearse et al. 2012). Sequence data from 11 additional downy mildew samples on Impatiens spp. covering the same three molecular markers were obtained from NCBI GenBank (Görg et al. 2017; accessions MF372718 to MF372750) and from the reference genome of Plasmopara viticola isolate INRA-PV221 (assembly ASM169559v1). For each marker, sequences were aligned using MUSCLE (Edgar 2004) and viewed in AliView v1.18.1 (Larsson 2014) to evaluate alignment quality. Internal gaps were left in the alignment and treated as missing data in downstream analysis. Alignments from the three markers were concatenated using FaBox (Villesen 2007; http://users-birc.au.dk/biopv/ php/fabox/).

A maximum likelihood phylogenetic tree was constructed from the concatenated alignment using RAxML v8.0.0 (Stamatakis 2014). Different substitution models were evaluated using jModelTest 2 (Darriba et al. 2012) and selected based on Akaike information criterion values and the ability to use a given model in RAxML. Tree construction used a general time reversal model with gamma distributed rate variation among sites and estimate of invariable sites (GTRGAMMAI in RAxML) and 100 bootstrap replications. Trees were visualized using the program FigTree v1.4.3 (http://tree.bio.ed.ac.uk/software/ figtree/) and the R package APE (Paradis et al. 2004; R Development Core Team 2015).

Data and resource curation. Fifty-four herbarium voucher specimens corresponding to new P. obducens samples collected in this study were deposited in the U.S. National Fungus Collections (BPI). DNA sequences from cloned amplicons generated from the IDM498 and IDM604 assays from the three historical herbarium samples were not deposited in NCBI GenBank as they do not meet the minimum length requirements of 200 nucleotides; these sequences are provided in the Supplementary Fig. S1. All other nucleotide sequences have been deposited in GenBank (accession numbers MG805315 to MG805338).

\section{Results}

Ribosomal DNA sequencing of $\boldsymbol{P}$. obducens from fresh collections on impatiens. Thirty-seven samples of $P$. obducens collected between 2007 and 2013 were assessed by Sanger sequencing of the DC6/Plob3 rDNA PCR amplicons, which corresponded to a portion of the partial 18S, ITS1, 5.8S, and ITS2 regions of the nuclear rDNA. PCR amplification yielded products of approximately $1,100 \mathrm{bp}$ when visualized on agarose gels (data not shown). Sanger sequencing reactions primed directly from the DC6/Plob3 rDNA amplicons produced chromatograms with mixed peaks at some nucleotide sites (data not shown). These mixed peaks might have been due to allelism and/or the presence of more than a single individual genotype in the sample. Therefore, all subsequent nucleotide sequencing data from nuclear loci reported in this study were generated from cloned amplicons.

A total of 150 DC6/Plob rDNA clones were sequenced from the 37 $P$. obducens samples, as summarized in Supplementary Table S3. BLASTn searches against NCBI GenBank databases using the most common rDNA haplotype (H30 haplotype, $n=54$ ) as the query showed that the sequence shared 99 to $100 \%$ identity with specimens of $P$. obducens (DQ665666, EF553506 and KF366378 to KF366380; Crouch et al. 2014; Voglmayr and Constantinescu 2008), and 95\% identity with a voucher specimen of $P$. nivea (EF553507; Voglmayr and Constantinescu 2008). Relatively high levels of nucleotide identity ( 88 to $92 \%$ ) were also observed between the $P$. obducens rDNA amplicon sequences and other oomycete genera that cause downy mildew diseases, including Bremia lactucae (e.g., DQ235794), Hyaloperonospora parasitica (e.g., AY211008), Novotelnova scorzonerae (KT249142), Peronospora belbarii (KJ960193), and Pe. pulveracea (FJ384778; Choi and Thines 2015; Choi et al. 2003; Petrželová et al. 2015; Warfield et al. 2009).

Seventy-two unique rDNA haplotypes were identified from the 150 P. obducens clone sequences. Despite the fact that $50 \%$ of the 
clones possessed unique haplotypes, nucleotide diversity was low among the $P$. obducens samples. With only one exception, pairwise comparisons between the $72 P$. obducens rDNA haplotypes showed a shared nucleotide identity of $98.8-99.9 \%$. The sole exception, haplotype H56, corresponding to P. obducens sample H12_194P1 clone 1, shared only $93.4-94.1 \%$ nucleotide identity with the other $P$. obducens haplotypes. For the 26 P. obducens samples where two or more clones were sequenced, there was variation between cloned sequences. For example, sample CTIDM3, from which nine clones were sequenced, produced eight haplotypes (H19, H48 to H54) that differed from one another by 2 to $10 \mathrm{bp}(<0.01 \%$ overall difference). From sample FL1, 27 clones produced just three haplotypes $(\mathrm{H} 7, \mathrm{H} 30, \mathrm{H} 55)$ that differed by 3 to $11 \mathrm{bp}(\leq 0.01 \%$ overall difference).

Cluster analysis of the $P$. obducens rDNA amplicon sequence dataset showed that the 72 unique haplotypes formed three main groups, which were designated G1, G2, and G3 rDNA groups (Fig. 1). Sequences in the G1 rDNA group were derived from 15 clones with 14 unique haplotypes. The G1 group clones originated from three locations: two in Costa Rica and one in the United States (Southern California). Sequences in the G2 rDNA group were derived from 104 clones and included 34 unique haplotypes. The G2 clones originated from 28 locations across the United States and one Australian location. Sequences in the G3 rDNA group were derived from 22 clones and included 15 unique haplotypes. The G3 clones originated from five locations in the northeastern United States. There were also nine haplotypes that fell at intermediate positions between rDNA groups G1, G2, and G3 (Fig. 1).

Not all of the DC6/Plob rDNA haplotypes from within individual locations fell within the same rDNA group. Nine locations yielded haplotypes that fell within the $\mathrm{G} 2$ group and at intermediate positions between the three main groups in the median joining network. Three locations yielded haplotypes that grouped with the G2 rDNA group and the G3 rDNA group (Fig. 1).

Endpoint SNP genotyping. To analyze rDNA profiles from 1,000 downy mildew samples, a set of custom TaqMan SNP genotype assays were developed to detect polymorphisms across the sequenced rDNA ITS region described above. The four SNPs selected for use in the endpoint SNP genotype assays are referred to as assays IDM134, IDM498, IDM604, and IDM1020 hereafter based on their position in preliminary sequence alignments (Table 2). The sizes of the amplicons as well as primer and probe sequences are found in Table 2. When used in combination, these four SNPs corresponded with the unique rDNA profiles of G1, G2, and G3 exhibited in the multiple sequence alignment generated from the 150 cloned rDNA amplicons from $P$. obducens, and were used in the cluster analysis (Fig. 1).

A total of 19 unique SNP genotypes were present in 1,000 samples (984 P. obducens and 16 samples from outgroup species, Table 1), with 10 genotypes representing samples classified as $P$. obducens based on morphology (e.g., herbarium specimens) or association with modern IDM epidemics. The 10 P. obducens SNP genotypes not including any outgroup species were also coded as rDNA genotypes to coincide with the G1, G2, and G3 rDNA groups determined from clustering rDNA amplicon data (Fig. 1, see above). For consistency, the remaining seven $P$. obducens SNP genotypes were coded as G4 to G10 rDNA genotypes (Table 3). As shown in Table 3, six samples initially classified as P. obducens shared SNP genotypes with the outgroup species. Even though genetic divergence among samples was low, (i.e., genotypes were separated by relatively few differences: one to four changes), B. megasperma, Pe. alsinearum, and $P$. constantinescui genotypes formed distinct clusters relative to $P$. obducens (Fig. 2).

Overall, three rDNA genotypes represented over $95 \%$ of the P. obducens samples (Fig. 2, Table 3). The G2 and G3 rDNA genotypes, corresponding to the G2 and G3 rDNA groups, represented $90 \%$ of the samples. The third most frequent rDNA genotype, G7, did not directly correspond to any of the three rDNA groups previously defined from the cloned sequences. In the median joining network topology (Fig. 2), the G7 genotype was closely related to the G2 rDNA genotype. Only nine samples were classified in the G1 rDNA genotype. The six remaining rDNA genotypes were represented by five or fewer samples (Table 3). Interestingly, two samples taken from the herbarium specimen preserved from the initial 2004 IDM outbreak on I. walleriana in Tennessee were different from each other and any of the more frequently observed rDNA genotypes.

The distribution of rDNA genotypes was uneven between samples collected before and during the twenty-first century outbreaks of IDM (post-epidemics) in the United States. All 10 P. obducens rDNA genotypes were observed from the samples of $P$. obducens from the twenty-first century epidemics, while only two rDNA genotypes were observed from historical samples (e.g., those collected 2004

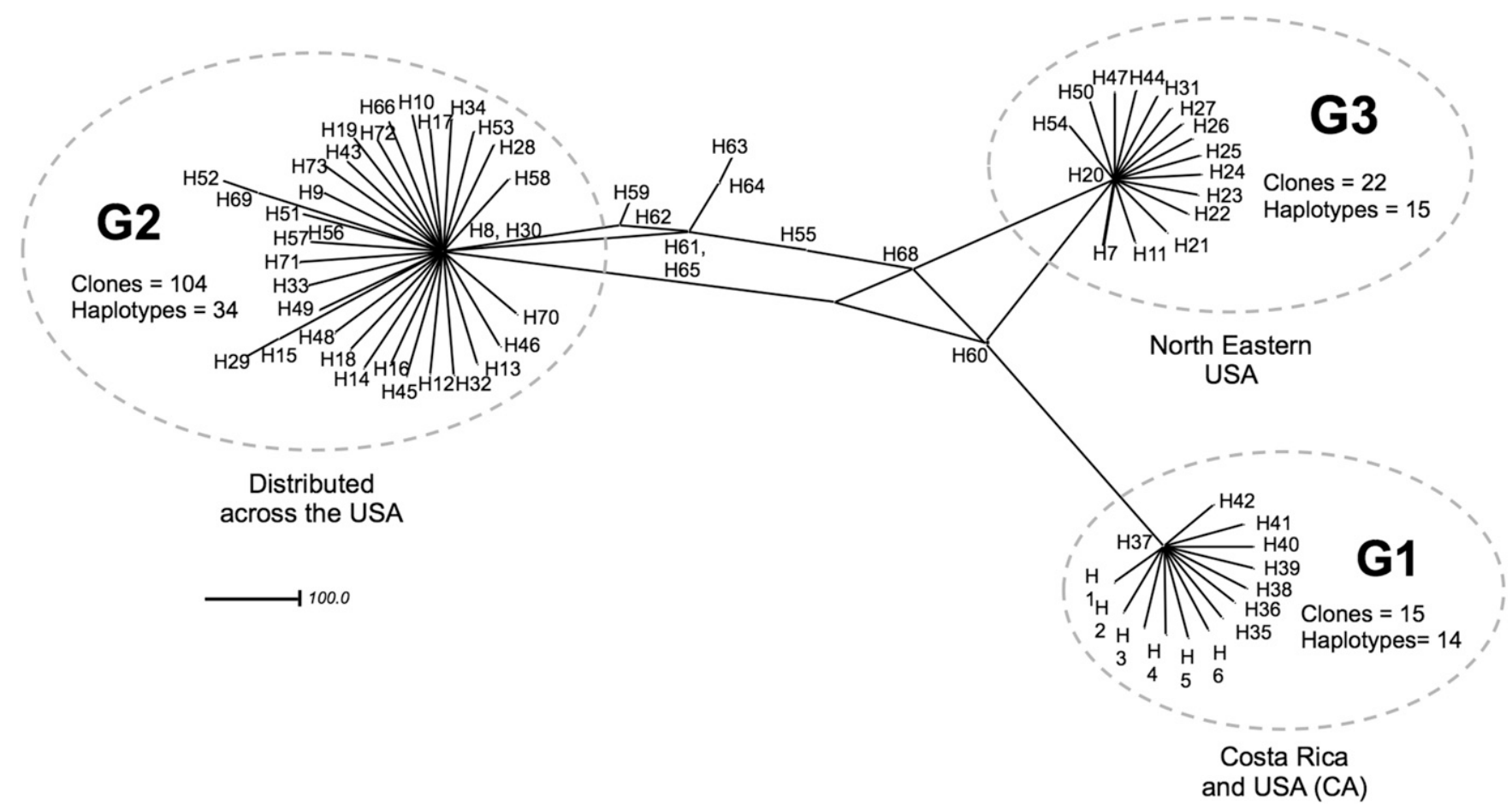

Fig. 1. Median joining network constructed from $150 \mathrm{rDNA}$ amplicon sequence data representing 72 unique haplotypes of Plasmopara obducens sensu lato. Each tip label represents a unique rDNA haplotype. The G1, G2, and G3 clusters represent rDNA groups and correspond to the G1, G2, and G3 rDNA genotypes. 
or earlier) (G3 and G4, Fig. 2). Approximately $40 \%$ of the G3 rDNA genotypes were from historical $P$. obducens samples. One of the five samples with the G4 rDNA genotype was also observed from a historical sample. Overall, the presence of only two genotypes in historical samples highlighted the increase in the number of $P . o b d u$ cens rDNA genotypes recovered from modern samples.

The different genotypes also displayed little evidence of differentiation based on host origin. Aside from the recovery of the nine

Table 3. Endpoint rDNA SNP genotypes generated at four nucleotide sites within the nuclear ribosomal DNA from Plasmopara obducens and related downy mildew species in Plasmopara and Bremiella

\begin{tabular}{|c|c|c|c|c|c|c|c|c|}
\hline Species $^{\mathrm{a}}$ & Samples ${ }^{b}$ & SNP genotype ${ }^{c}$ & rDNA genotype ${ }^{d}$ & IDM134 & IDM498 & IDM604 & IDM1020 & Het. Pos. ${ }^{f}$ \\
\hline P. obducens & 741 & $\mathrm{~F}$ & G2 & $\mathrm{AG}$ & GG & $\mathrm{AT}$ & $\mathrm{AT}$ & 3 \\
\hline P. obducens & 148 & $\mathrm{~A}$ & G3 & GG & GG & $\mathrm{AA}$ & TT & 0 \\
\hline P. obducens & 69 & $\mathrm{G}$ & G7 & $\mathrm{AG}$ & GG & AT & $\mathrm{AA}$ & 2 \\
\hline P. obducens & 9 & $\mathrm{E}$ & G1 & GG & $\mathrm{AA}$ & $\mathrm{AA}$ & $\mathrm{AT}$ & 1 \\
\hline P. obducens & 5 & $\mathrm{D}$ & G4 & GG & GG & $\mathrm{AA}$ & AT & 1 \\
\hline P. obducens & 2 & $\mathrm{~J}$ & G9 & AA & GG & TT & $\mathrm{AA}$ & 0 \\
\hline P. obducens & 1 & 4 & G10 & GG & $\mathrm{AA}$ & $\mathrm{AA}$ & $\mathrm{AA}$ & 0 \\
\hline P. obducens & 1 & 2 & G5 & GG & $\mathrm{AG}$ & $\mathrm{AA}$ & AT & 2 \\
\hline P. obducens & 1 & 6 & G6 & $\mathrm{AG}$ & $\mathrm{AG}$ & AT & AT & 4 \\
\hline P. obducens & 1 & 5 & G8 & $\mathrm{AG}$ & GG & AT & TT & 2 \\
\hline Peronospora alsinearum $(n=1)$ & 7 & $\mathrm{C}$ & & GG & GG & AT & AT & 2 \\
\hline \multicolumn{9}{|l|}{ P. constantinescui $(n=2)$} \\
\hline \multicolumn{9}{|l|}{ P. obducens $(n=4)$} \\
\hline P. constantinescui $(n=2)$ & 3 & B & & GG & GG & TT & $\mathrm{AT}$ & 1 \\
\hline \multicolumn{9}{|l|}{ P. obducens $(n=1)$} \\
\hline B. megasperma & 3 & $\mathrm{~K}$ & & AA & GG & AT & $\mathrm{AA}$ & 1 \\
\hline B. megasperma & 2 & I & & AA & GG & AT & AT & 2 \\
\hline B. megasperma $(n=1)$ & 2 & $\mathrm{H}$ & & AA & GG & TT & AT & 1 \\
\hline \multicolumn{9}{|l|}{ P. obducens $(n=1)$} \\
\hline P. constantinescui & 2 & 3 & & GG & GG & AT & TT & 1 \\
\hline P. constantinescui & 1 & 1 & & GG & $\mathrm{AA}$ & AT & TT & 1 \\
\hline B. megasperma & 1 & 7 & & AA & GG & AA & AT & 1 \\
\hline B. megasperma & 1 & 8 & & $\mathrm{AA}$ & GG & $\mathrm{AA}$ & TT & 0 \\
\hline
\end{tabular}

a Taxonomic classification of original sample.

${ }^{\mathrm{b}}$ Number of samples out of 1,000 total classified to the genotype in SNP genotype column.

${ }^{c}$ Genotype label output from the GenAlEx genotyping analysis corresponding to the four SNPs in columns labeled with e.

${ }^{\mathrm{d}}$ Reclassification of SNP genotypes to correspond to the G1, G2, and G3, rDNA haplotypes. G4 to G10 do not correspond to rDNA groups, but represent SNP genotypes for samples originally classified as $P$. obducens.

e One of four targeted SNPs, with letters indicating homozygosity (e.g., GG) or heterozygosity (e.g., AG) corresponding to the genotype in the column labeled with c.

${ }^{\mathrm{f}}$ The total number of the four SNPs that display heterozygosity.

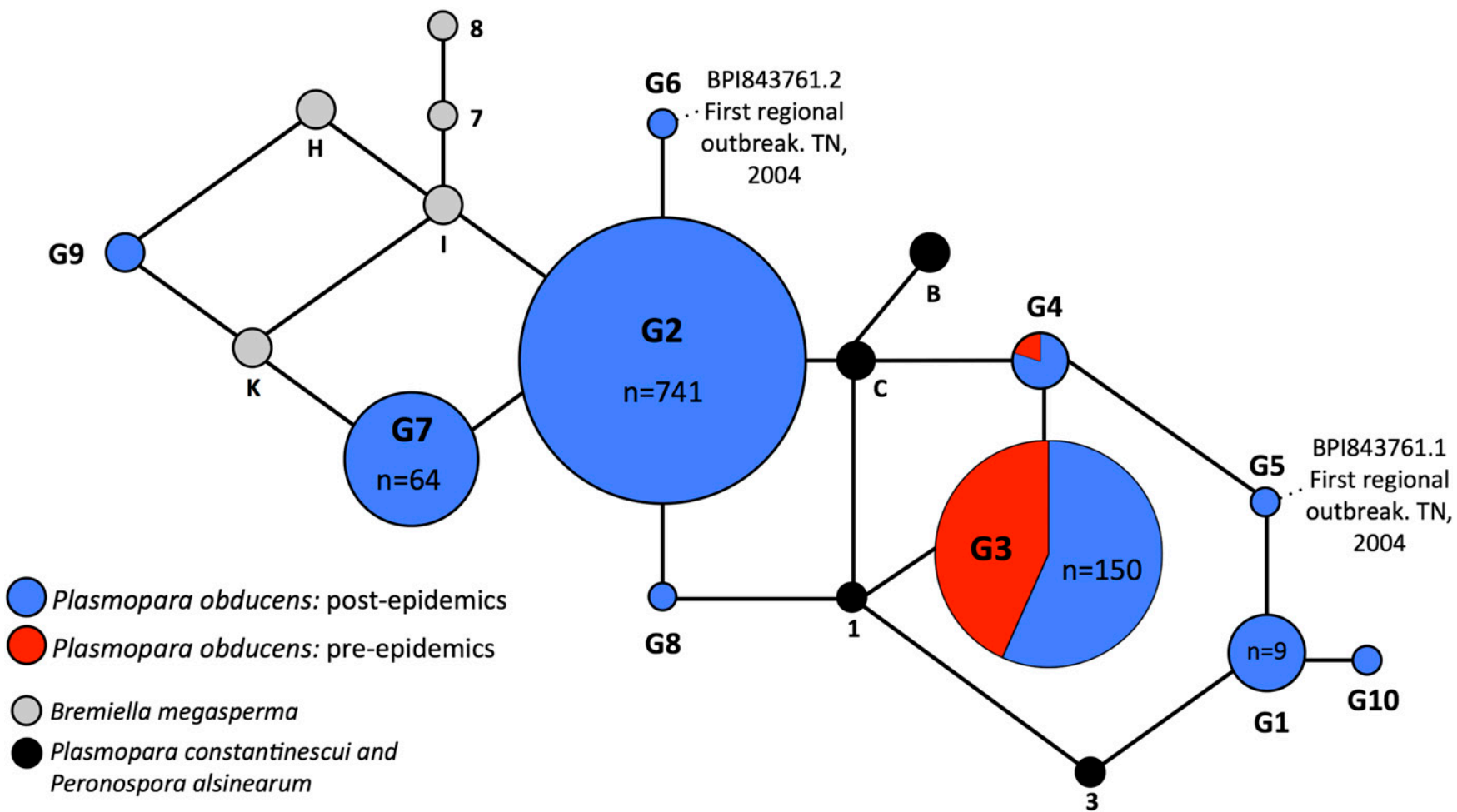

Fig. 2. Median joining network constructed using SNP genotypes from 1,000 downy mildew samples generated from four individual SNP genotyping assays. Network topology reflects output from the program Network, while size of individual nodes are rescaled for readability. 
samples of G1 rDNA genotypes exclusively from I. walleriana, all of the most frequent rDNA genotypes were found on at least two different species of Impatiens. The most common rDNA genotypes G2, G3, and G7 were each found infecting I. balsamina and I. walleriana, and also from I. capensis plants that were artificially inoculated using $P$. obducens spores harvested from I. walleriana. Through similar artificial inoculations, G3 genotypes were also found to infect I. flanaganiae and I. hochstetteri and Impatiens sp. 'Blue Angel'. In addition, of the different plant species, only I. walleriana was infected by each of the 10 P. obducens rDNA genotypes (Table 3). Interestingly, the oldest sample in this study, collected in 1877 on I. noli-tangere as part of the original P. obducens description (BPI784609) shared the same G3 rDNA genotype as all of the other samples collected from this same host.

Analysis of the rDNA genotypes also showed that, although rare, infections by multiple genotypes occurred on individual plants, as different genotypes of $P$. obducens were found on at least $10 \%$ of infected plants. Multiple genotypes were present on samples from Hawaii, Indiana, Massachusetts, Michigan, New Jersey, New York, and Rhode Island. The majority of multiple genotypes were detected on I. walleriana plants, with few occurrences on I. balsamina and I. capensis.

Phylogenetic analysis. A phylogenetic analysis was performed using sequence data from the ITS, $\cos 2$, and $\cos 2-1$ spacer regions of the nuclear and mitochondrial genomes of nine P. obducens samples collected in this study, combined with previously published data from 11 samples of Plasmopara from Impatiens sp. (Görg et al. 2017). The nine samples from the present study included three samples from I. balsamina (G2, G3, and G7 rDNA genotypes), two samples from I. walleriana (both G1 genotypes), and four samples from I. noli-tangere (all G3 genotypes). Based on the resultant maximum likelihood phylogeny, the samples formed four well-supported clades (bootstrap value of 96 or higher) (Fig. 3). Two samples (IN$3 \mathrm{~A}$ and $\mathrm{IN}-3 \mathrm{~F}$ ) from I. balsamina formed a clade with the type specimen of $P$. destructor Görg \& Thines (GLM-F107554; Fig. 3). One sample from I. balsamina (MD15.1.10) formed a clade with the type specimen of $P$. velutina Görg \& Thines (GLM-F107553; Fig. 3). Two samples from I. walleriana (G1.153 and G1.49) formed a sister clade to the clade containing the type specimen of $P$. destructor and samples from I. balsamina. Of the four samples from I. noli-tangere, three grouped with the clade of $P$. obducens s. str. samples used by Görg et al. (2017) to distinguish $P$. velutina and $P$. destructor from $P$. obducens. It should be noted that type materials of $P$. obducens were not used in the analysis of Görg et al. (2017). Herbarium specimens collected as part of the type materials used for the original description of $P$. obducens (BPI784609; Rabenhorst Fungi Europaei \#2344 exsiccati collection, U.S. National Fungus Collections) did not produce amplicons useable for sequencing or phylogenetic analysis in this study; however, the rDNA SNP genotype from BPI784609 indicates that it belongs to the G3 rDNA genotype.

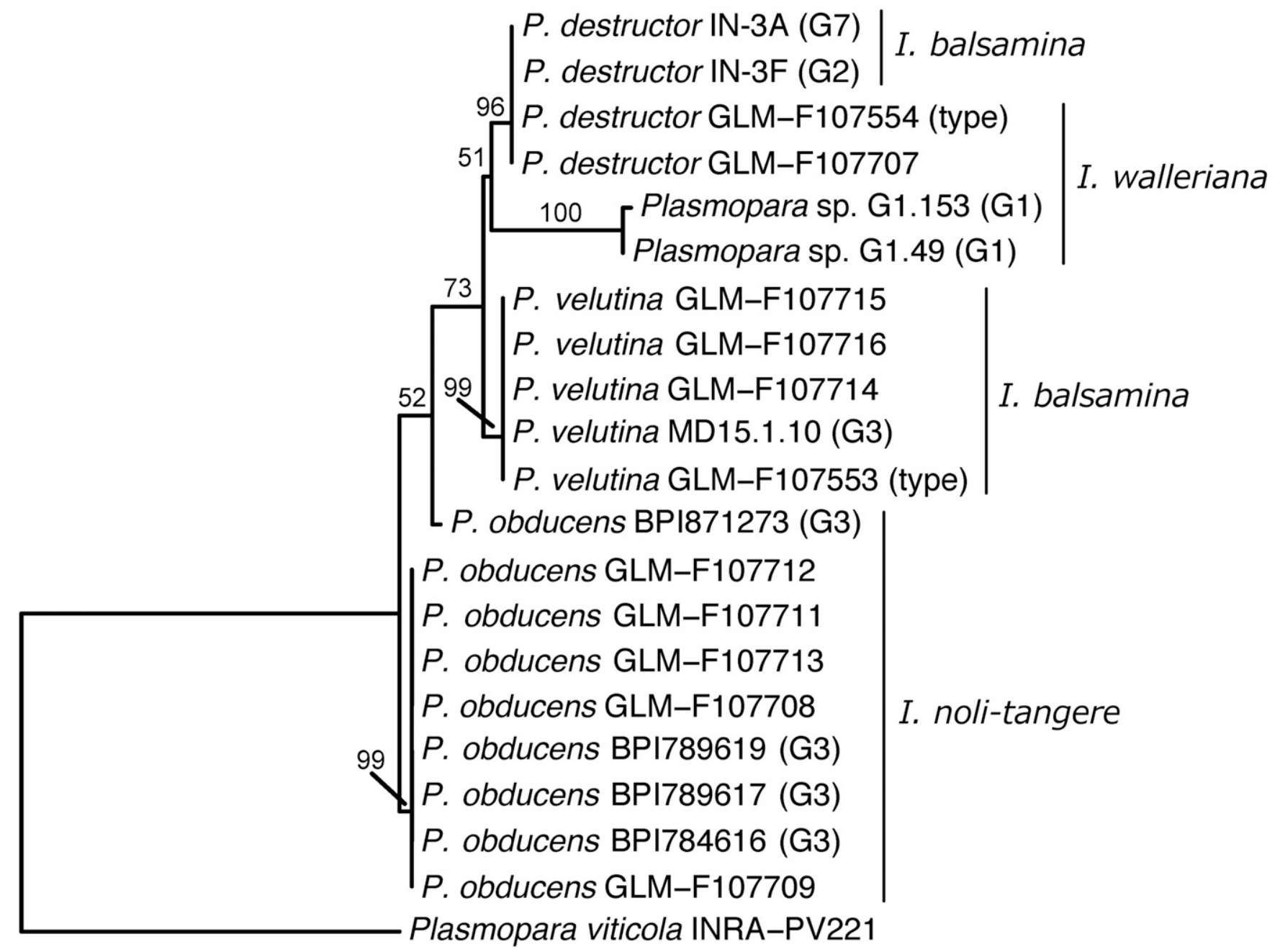

Fig. 3. Maximum likelihood phylogeny constructed from concatenated ITS, cox2 and cox2-spacer data from 20 samples of downy mildew pathogens in the genus Plasmopara on three Impatiens species. Numbers above branches indicate bootstrap support values based on 100 replicates. Samples from the current study are appended with parentheses indicating their rDNA genotype (i.e., G1, G2, G3, or G7). Samples from Görg et al. (2017) are indicated by 'GLM' in the name. Type specimens used to describe P. destructor and P. velutina Görg et al. (2017) are indicated in parentheses. Impatiens balsamina, I. noli-tangere, and I. walleriana indicate the plant host origin for each sample. Plasmopara viticola INRA-PV221 serves as an outgroup. 
One sample from I. noli-tangere (BPI871273), collected from South Korea in 2005, did not fall within any of the four clades (Fig. 3). None of the individual gene trees constructed from the ITS, $\cos 2$, and cox2-1 datasets could independently resolve all three species described by Görg et al. (2017) into well supported phylogenetic clades (Supplementary Fig. S2).

\section{Discussion}

The primary question of this research was to determine if the downy mildew pathogen causing the recent twenty-first century IDM epidemics on I. walleriana is the same organism that was described from historical herbarium records from multiple noncultivated species of Impatiens (e.g., I. biflora, I. palida, I. fulva, I. noli-tangere). As modern IDM samples were infected with all 10 of the P. obducens rDNA genotypes and historical IDM samples were infected with only two of these 10 major rDNA genotypes (G3 and G4), the increased presence of the most dominant and widespread IDM rDNA genotypes (e.g., the heterozygous G2 and G7) after 2004 may represent the primary source of genetic variants of the pathogen responsible for twenty-first century IDM epidemics. The homozygous G3 rDNA genotypes found on the majority of the historical samples worldwide were also routinely recovered in modern samples of the disease affecting $I$. walleriana collected in the northeastern region of the United States. These findings indicate that even though certain rDNA genotypes are only found in samples from the recent epidemic affecting I. walleriana, downy mildew pathogens historically documented on Impatiens spp. in the United States and globally still live in the environment alongside the more contemporary genotypes.

The evidence that modern $P$. obducens infecting $I$. walleriana is genetically different from historical herbarium specimens of $P$. obducens shares similarities with other downy mildews in the Peronosporaceae and has implications for managing these pathogens. Within the genus Plasmopara, modern $P$. halstedii infecting Rudbeckia spp. are genetically differentiated from historical herbarium specimens of $P$. halstedii infecting this same host species (Rivera et al. 2016b). Similarly, the re-emergence of cucurbit downy mildew in the United States caused by Pseudoperonospora cubensis is likely due to the displacement of historical pathogen genotypes by emerging genotypes not previously found in the United States (Thomas et al. 2017). Overall, the significant shifts in pathogen genotypes associated with the emergence or re-emergence of downy mildews on known and novel hosts highlights the importance for continued monitoring of genetic variation among these pathogens. Further integration of those data with research on the life-cycle of these pathogens will refine our understanding of disease epidemiology and contribute to the development of robust disease management strategies.

The secondary question of this work was to evaluate evidence for host specificity among downy mildews infecting Impatiens species. Host specificity among pathogens causing downy mildews on other plant host species is documented from several studies based on phylogenetic affinities (Choi and Thines 2015; Choi et al. 2015; Göker et al. 2007; Rivera et al. 2016b; Rouxel et al. 2013, 2014; Runge et al. 2011; Thines and Choi 2016) and was recently used as a basis for the description of two new species of Plasmopara as specific to I. balsamina and I. walleriana, distinct from the species originally described from I. noli-tangere (Görg et al. 2017). Based on the recovery of all three of the most common rDNA genotypes from IDM samples collected from I. balsamina, I. capensis, and I. walleriana, we found little evidence for host specificity on those species in the present study. The only exception was the G1 rDNA genotype, which was only identified from I. walleriana. However, the small number of samples $(n=9)$ encompassed by the G1 rDNA genotype limits our ability to confidently assert its host specific infection of $I$. walleriana.

The recovery of the same $P$. obducens genotypes from multiple Impatiens species and different pathogen genotypes from the same host species highlights a lack of host specificity. Although downy mildews are often regarded as highly host-specific pathogens, this specificity is not always found at the host species level. For example, grape downy mildew caused by Plasmopara viticola can be found on different species of cultivated and native Vitis (Farr and Rossman 2018). In addition, isolates from different phylogenetic clades within $P$. viticola show variation in the number of different Vitis spp. they infect, and representatives from different phylogenetic clades can be recovered from the same host species (Rouxel et al. 2013, 2014). Considering these observations, inferring host specificity of poorly understood downy mildews like $P$. obducens should be done with caution and only when an appropriate sampling of the pathogen has been performed that includes observations over multiple years and from multiple geographic locations.

A supplementary analysis was added to this work to determine how conclusions drawn from rDNA genotyping data compare with recent phylogenetic studies that suggested high levels of host specialization among different phylogenetic clades in $P$. obducens. Sequencing of rDNA and two molecular markers from the mtDNA $\operatorname{cox} 2$ region provided evidence that only the infection of $I$. nolitangere species appears to be limited to an individual phylogenetic clade of Plasmopara, which includes only isolates from the G3 rDNA SNP genotype (Fig. 3, Görg et al. 2017). As an individual sample from this host did not fall within the primary clade, future phylogenetic studies would need to include a greater number of samples from I. noli-tangere. Infection of the remaining Impatiens species (I. balsamina and I. walleriana) is not limited to any phylogenetic group of Plasmopara. In particular, we found that samples with similar genotypes as the recently described species $P$. destructor are present on both I. walleriana and I. balsamina. Plasmopara genotypes originally harvested from I. walleriana plants were capable of causing infection on plants from other species of Impatiens, including I. arguta, I. auricoma, I. capensis, I. flanaganiae, and I. omeiana. In addition, we identified a new sister clade (G1 rDNA genotypes) to $P$. destructor that is also capable of infecting I. walleriana. Taken together, these results demonstrate the species described as $P$. destructor is not limited to $I$. walleriana and that a second phylogenetic clade of downy mildew pathogens is also found on this host. These results further demonstrate a lack of host specificity of isolates from modern collections of IDM on I. walleriana and I. balsamina, and conflict with the conclusions of Görg et al. (2017), who used this trait as one of three criteria (the other two being morphological and phylogenetic differences) to describe these as two novel species of downy mildews.

Aside from potential inconsistencies regarding the proposed host specificity of the new Plasmopara species on I. walleriana and I. balsamina described above, the conclusions regarding species-level diversification on Impatiens sp. based on morphological characteristics warrant additional consideration. Although significant differences were reported based on sporangia and sporangiophore morphology among the three proposed Plasmopara species when large numbers of characters were measured (Görg et al. 2017), these differences may simply be due to the recovery of the downy mildew pathogens from different host species, or a result of plasticity due to variable environmental conditions, especially given the wide range of measurements recorded and the extensive overlap of characteristics observed (Runge and Thines 2011). In addition, morphological characterizations did not include the type specimen of $P$. obducens described in the 1800s (Schröeter 1877), which limits the power of the measurements used to differentiate $P$. obducens from $P$. destructor and $P$. velutina. Indeed, measurements obtained from the original $P$. obducens syntype collections from I. noli-tangere made by Schröeter and archived at the U.S. National Fungus Collection in Beltsville, MD shows similarities in morphological characteristics across all of the proposed Plasmopara species on Impatiens (Rabenhorst Fungi Europaei \#2344 exsiccati collection, data available upon request). Broadly overlapping ranges from the surveyed morphological characters effectively precludes the unambiguous differentiation of samples as distinct species (Görg et al. 2017), and would render any type of confident species-level identification within a nonmolecular setting such as a disease diagnostic clinic impossible. Considering this information, and in combination with observed inconsistencies in host association criteria, the recent taxonomic differentiation of P. obducens and other proposed Plasmopara species from Impatiens 
may not be practically aligned with biologically significant groups. This is compounded by the fact that only the combined ITS/cox $2 /$ cox2-1 spacer phylogeny consistently provides support for differentiation of $P$. obducens s. str., $P$. destructor, and $P$. velutina. With the exception of the G1 rDNA genotypes from I. walleriana, individual gene trees provided only limited support for additional species-level subdivisions, although species-level hypotheses were not refuted by these analyses. Taken together, these data suggest a more conservative approach for species delimitation may be warranted for this group of organisms (Carstens et al. 2013) until a more comprehensive multilocus phylogenetic analysis can be completed.

This research also raises some important methodological considerations for studying genetic variation of downy mildews. Although allelic variation from nuclear loci is not typically addressed in molecular phylogenetic studies of the Peronosporaceae, including the recent taxonomic investigations of Plasmopara on Impatiens, our findings show that the diploid nature of these organisms needs to be explicitly addressed in order to eliminate potential sources of error. In the present study, accounting for heterozygosity within the rDNA using cloned rDNA amplicons and endpoint genotype assays showed that the rDNA region is heterozygous at several nucleotide sites in several genetic groups of $P$. obducens s.l. and three other species evaluated in this study: B. megasperma, Pe. alsinearum, and $P$. constantinescui. Of the 13 unique $P$. obducens rDNA genotypes observed from the four SNP endpoint genotype profiles, only three rDNA groups were homozygous at all four sites (G3, $\mathrm{G} 9, \mathrm{G} 10 ; n=151)$. The remaining 10 P. obducens rDNA groups, comprising 833 samples, would not have been accurately discriminated without incorporating allelic variation into the analyses, as these groups were heterozygous at least one of the four SNPs. The presence of multiple haplotypes from individual leaf samples also raises questions as to the nature of host infection by $P$. obducens. One explanation is that the samples represent a single $P$. obducens individual that displays variation across the different copies of rDNA loci in its nuclear genome. Such intragenomic variation in multiple copy rDNA loci has been observed in other eukaryotes (Bik et al. 2013; Simon and Weiss 2008). An alternative explanation is that individual plant samples are infected with more than one $P$. obducens individual. Future work will need to employ methods that provide information on the frequency of different alleles and ploidy of the pathogens to resolve these issues.

This work provides the first analysis of genetic variation among large populations of the pathogen causing downy mildew on Impatiens species, with particular focus on samples from recent IDM epidemics in the United States and historical downy mildew samples on noncultivated Impatiens species. Overall, the genetic variation of these organisms highlights the presence of genotypes commonly associated with recent epidemics, but not present in historical herbarium specimens. This observation provides evidence that the genetic variants of the pathogen in modern samples may be responsible for the twenty-first century epidemics. Despite this evidence, the rDNA SNP genotyping and complementary phylogenetic analysis performed herein are relatively low-resolution and likely fail to fully capture genetic variation across downy mildew pathogen genomes. Future research should apply higher resolution genotyping methods (e.g., simple sequence repeat markers or genotype-by-sequencing) to measure genetic variation among the organisms causing downy mildew on impatiens. Polymorphic simple sequence markers mined from the genome of $P$. obducens have been developed, and their application may provide the resolution required to go beyond single genetic loci to model population processes and divergence (SalgadoSalazar et al. 2015). Performing these higher resolution genotyping methods will provide further insight into the evolution of these destructive pathogens and may contribute to the development of IDM disease control strategies.

\section{Acknowledgments}

We are grateful to numerous collaborators who provided plant samples and the U.S. National Fungus Collections.

\section{Literature Cited}

Bandelt, H.-J., Forster, P., and Röhl, A. 1999. Median-joining networks for inferring intraspecific phylogenies. Mol. Biol. Evol. 16:37-48.

Baysal-Gurel, F., Taylor, N. J., Chatfield, J., and Miller, S. A. 2012. First report of impatiens downy mildew caused by Plasmopara obducens in Ohio. Plant Dis. 96:1699.

Bik, H. M., Fournier, D., Sung, W., Bergeron, R. D., and Thomas, W. K. 2013. Intra-genomic variation in the ribosomal repeats of nematodes. PLoS One 8: e78230.

Bonants, P. J. M., Hagenaar-de, W. M., van Gent-Pelzer, M. P. E., Lacourt, I., Cooke, D. E. L., and Duncan, J. M. 1997. Detection and identification of Phytophthora fragariae Hickman by the polymerase chain reaction. Eur. J. Plant Pathol. 103:345-355.

Bulajić, A., Vučurović, A., Stanković, I., Ristić, D., Jović, J., Stojković, B., and Krstić, B. 2011. First report of Plasmopara obducens on Impatiens walleriana in Serbia. Plant Dis. 95:491.

Carstens, B. C., Pelletier, T. A., Reid, N. M., and Satler, J. D. 2013. How to fail at species delimitation. Mol. Ecol. 22:4369-4383.

Choi, Y.-J., Beakes, G., Glockling, S., Kruse, J., Nam, B., Nigrelli, L., Ploch, S., Shin, H.-D., Shivas, R. G., Telle, S., Voglmayr, H., and Thines, M. 2015 Towards a universal barcode of oomycetes - a comparison of $\operatorname{cox} 1$, and $\operatorname{cox} 2$ loci. Mol. Ecol. Resour. 15:1275-1288.

Choi, Y.-J., Han, J.-G., Park, M. J., and Shin, H.-D. 2003. Diversity of the Hyaloperonospora parasitica complex from core brassicaceous hosts based on ITS rDNA sequences. Mycol. Res. 107:1314-1322.

Choi, Y.-J., Han, J.-G., Park, M. J., and Shin, H.-D. 2009. Downy mildew of Impatiens balsamina and I. walleriana in Korea. Plant Pathol. J. 25:433.

Choi, Y.-J., and Thines, M. 2015. Host jumps and radiation, not co-divergence drives diversification of obligate pathogens. A case study in downy mildews and Asteraceae. PLoS One 10:e0133655.

Cohen, Y., van den Lagenberg, K. M., Wehner, T. C., Ojiambo, P. S., Hausbeck, M., Quesada-Ocampo, L. M., Lebeda, A., Sierotzi, H., and Gisi, U. 2015. The resurgence of Pseudoperonospora cubensis: The causal agent of cucurbit downy mildew. Phytopathology 105:998-1012.

Conner, K. N., Olive, J., Hagan, A. K., Zhang, L., and Bloodworth, M. E. 2014. First report of impatiens downy mildew caused by Plasmopara obducens in Alabama. Plant Dis. 98:1006.

Crouch, J. A., Ko, M. P., and McKemy, J. M. 2014. First report of impatiens downy mildew outbreaks caused by Plasmopara obducens throughout the Hawaiian Islands. Plant Dis. 98:696.

Cunnington, J. H., Aldaoud, R., Loh, M., Washington, W. S., and Irvine, G. 2008 First record of Plasmopara obducens (downy mildew) on impatiens in Australia. Plant Pathol. 57:371.

Darriba, D., Taboada, G. L., Doalla, R., and Posada, D. 2012. jModelTest 2: More models, new heuristics and parallel computing. Nat. Methods 9:772.

Edgar, R. C. 2004. MUSCLE: Multiple sequence alignment with high accuracy and high throughput. Nucleic Acids Res. 32:1792-1797.

Farr, D. F., and Rossman, A. Y. 2018. Fungal Databases, Systematic Mycology and Microbiology Laboratory, ARS, USDA. Retrieved January 11, 2018 , from https://nt.ars-grin.gov/fungaldatabases/

Göker, M., Voglmayr, H., Riethmüller, A., and Oberwinkler, F. 2007. How do obligate parasites evolve? A multi-gene phylogenetic analysis of downy mildews. Fungal Genet. Biol. 44:105-122.

Görg, M., Ploch, S., Kruse, J., Kummer, V., Runge, F., Choi, Y.-J., and Thines, M. 2017. Revision of Plasmopara (Oomycota, Peronosporales) parasitic to Impatiens. Mycol. Prog. 16:791-799.

Hansen, M. A., Bush, E., Latimer, J., and Hong, C. 2013. Impatiens downy mildew. Virginia Cooperative Extension PPWS-19NP. Online: https://vtechworks.lib.vt. edu/handle/10919/48289.

Hudspeth, D. S., Nadler, S. A., and Hudspeth, M. E. 2000. A cox2 molecular phylogeny of the Peronosporomycetes. Mycologia 92:674-684.

Huson, D. H., and Bryant, D. 2006. Application of phylogenetic networks in evolutionary studies. Mol. Biol. Evol. 23:254-267.

Kearse, M., Moir, R., Wilson, A., Stones-Havas, S., Cheung, M., Sturrock, S., Buxton, S., Cooper, A., Markowitz, S., Duran, C., Thierer, T., Ashton, B., Mentjies, P., and Drummond, A. 2012. Geneious basic: An integrated and extendable desktop software platform for the organization and analysis of sequence data. Bioinformatics 28:1647-1649.

Kirschner, R. 2013. First record of Plasmopara obducens on Impatiens walleriana in Taiwan: A destructive disease or chance of limiting the competitive ability of an invasive plant? Plant Pathol. Quar. J. Fungal Biolog. 3:35-39.

Lane, C. R., Beales, P. A., O'Neill, T. M., McPherson, G. M., Finlay, A. R., David, J., Constantinescu, O., and Henricot, B. 2005. First report of impatiens downy mildew (Plasmopara obducens) in the UK. Plant Pathol. 54:243.

Larsson, A. 2014. AliView: A fast and lightweight alignment viewer and editor for large datasets. Bioinformatics 30:3276-3278

McGinnis, E., Kinzer, K., and LeBoldus, J. 2015. First report of impatiens downy mildew caused by Plasmopara obducens in North Dakota. Plant Dis. 99:1039.

McTaggart, A. R., Shuey, L. S., McKenna, S. G., Davis, R. I., and Shivas, R. G. 2015. Plasmopara sphagneticolae sp. nov. (Peronosporales) on Sphagneticola (Asteraceae) in Australia. Australas. Plant Pathol. 44:81-85. 
Morgan, R. J. 2007. Impatiens: The vibrant world of busy lizzies, balsams and touch-me-nots. Timber Press, Inc., Portland, Oregon.

Palmateer, A. J., Lopez, P., Seijo, T. E., and Peres, N. A. R. 2013. Severe outbreak of downy mildew caused by Plasmopara obducens on Impatiens walleriana in Florida. Plant Dis. 97:687.

Paradis, E., Claude, J., and Strimmer, K. 2004. APE: Analysis of phylogenetics and evolution in R language. Bioinformatics 20:289-290.

Peakall, R., and Smouse, P. E. 2012. GenAlEx 6.5: Genetic analysis in Excel. Population genetic software for teaching and research - an update. Bioinformatics 28:2537-2539.

Petróczy, M., Csejk, G., and Palkovics, L. 2012. First report of Plasmopara obducens causing downy mildew on Impatiens walleriana in Hungary. Plant Dis. 96:148.

Petrželová, I., Kitner, M., Dolezalova, I., Ondrej, V., and Lebeda, A. 2015. First report of basil downy mildew caused by Peronospora belbahrii in the Czech Republic. Plant Dis. 99:418.

R Development Core Team. 2015. R: A language and environment for statistical computing. R Foundation for Statistical Computing, Vienna, Austria.

Rivera, Y., Salgado-Salazar, C., Creswell, T., Ruhl, G., and Crouch, J. A. 2016a. First report of downy mildew caused by Peronospora sp. on Agastache in the United States. Plant Dis. 100:1249.

Rivera, Y., Salgado-Salazar, C., Gulya, T., and Crouch, J. A. 2016b. Newly emerged populations of Plasmopara halstedii infecting rudbeckia exhibit unique genotypic profiles and are distinct from sunflower-infecting strains. Phytopathology 106:752-761.

Rivera, Y., Salgado-Salazar, C., Windham, A. S., and Crouch, J. A. 2016c. Downy mildew on coleus (Plectranthus scutellarioides) caused by Peronospora belbahrii sensu lato in Tennessee. Plant Dis. 100:655.

Rouxel, M., Mestre, P., Baudoin, A., Carisse, O., Delière, L., Ellis, M. A., Gadoury, D., Lu, J., Nita, M., Richard-Cervera, S., Schilder, A., Wise, A., and Delmotte, F. 2014. Geographic distribution of cryptic species of Plasmopara viticola causing downy mildew on wild and cultivated grape in eastern North America. Phytopathology 104:692-701.

Rouxel, M., Mestre, P., Comont, G., Lehman, B. L., Schilder, A., and Delmotte, F. 2013. Phylogenetic and experimental evidence for host-specialized cryptic species in a biotrophic oomycete. New Phytol. 197:251-263.

Runge, F., Choi, Y.-J., and Thines, M. 2011. Phylogenetic investigations in the genus Pseudoperonospora reveal overlooked species and cryptic diversity in the $P$. cubensis species cluster. Eur. J. Plant Pathol. 129:135-146.

Runge, F., and Thines, M. 2011. Host matrix has a major impact on the morphology of Pseudoperonospora cubensis. Eur. J. Plant Pathol. 129:147156.

Salgado-Salazar, C., Rivera, Y., Veltri, D., and Crouch, J. A. 2015. Polymorphic SSR markers for Plasmopara obducens (Peronosporaceae), the newly emergent downy mildew pathogen of Impatiens (Balsaminaceae). Appl. Plant Sci. 3: 1500073.

Satou, M., Sugawara, K., Nagashima, S., Tsukamoto, T., and Matsushita, Y. 2013. Downy mildew of busy lizzie caused by Plasmopara obducens in Japan. J. Gen. Plant Pathol. 79:205-208.

Schröeter, J. 1877. Notizblatt für kryptogamische studien, nebst reportorium für kryptogamische literature. Hedwigia 9:129-135.

Shen, Y. M., Huang, J. H., and Liu, H. L. 2013. First report of downy mildew caused by Plasmopara obducens on impatiens in Taiwan. Plant Dis. 97:1512.
Simon, U. K., and Weiss, M. 2008. Intragenomic variation of fungal ribosomal genes is higher than previously thought. Mol. Biol. Evol. 25:2251-2254.

Stamatakis, A. 2014. RAxML version 8: A tool for phylogenetic analysis and postanalysis of large phylogenies. Bioinformatics 30:1312-1313.

Tanner, R., Ellison, C., Shaw, R., Evans, H., and Gange, A. 2008. Losing patience with impatiens: Are natural enemies the solution? Outlooks Pest Manag. 19: 86-91.

Thines, M., and Choi, Y.-J. 2016. Evolution, diversity, and taxonomy of the Peronosporaceae, with focus on the genus Peronospora. Phytopathology 106: 6-18

Thines, M., Göker, M., Oberwinkler, F., and Spring, O. 2007. A revision of Plasmopara penniseti, with implications for the host range of the downy mildews with pyriform haustoria. Mycol. Res. 111:1377-1385.

Thines, M., Telle, S., Ploch, S., and Runge, F. 2009. Identity of the downy mildew pathogens of basil, coleus, and sage with implications for quarantine measures. Mycol. Res. 113:532-540.

Thomas, A., Carbone, I., Choe, K., Quesada-Ocampo, L. M., and Ojiambo, P. S. 2017. Resurgence of cucurbit downy mildew in the United States: Insights from comparative genomic analysis of Pseudoperonospora cubensis. Ecol. Evol. 7: 6231-6246

Toppe, B., Brurberg, M. B., Stensvand, A., and Herrero, M. L. 2010. First report of Plasmopara obducens (downy mildew) on Impatiens walleriana in Norway. Plant Pathol. 59:800.

Vajna, L. 2011. First report of Plasmopara obducens on impatiens (Impatiens walleriana) in Hungary. New Dis. Rep. 24:13.

Verkley, G. J. M., Rossman, A., and Crouch, J. A. 2015. The role of herbaria and culture collections. Pages 205-225 in: Systematics and Evolution. The Mycota (A comprehensive treatise on fungi as experimental systems for basic and applied research). D. McLaughlin and J. Spatafora, eds. Springer, Berlin, Heidelberg.

Villesen, P. 2007. FaBox: An online toolbox for FASTA sequences. Mol. Ecol. Resour. 7:965-968.

Voglmayr, H., and Constantinescu, O. 2008. Revision and reclassification of three Plasmopara species based on morphological and molecular phylogenetic data Mycol. Res. 112:487-501

Voglmayr, H., Riethmüller, A., Göker, M., and Weiss, M. 2004. Phylogenetic relationships of Plasmopara, Bremia and other genera of downy mildew pathogens with pyriform haustoria based on Bayesian analysis of partial LSU rDNA sequence data. Mycol. Res. 108:1011-1024.

Voglmayr, H., and Thines, M. 2007. Phylogenetic relationships and nomenclature of Bremiella sphaerosperma (Chromista, Peronosporales). Mycotaxon 100:11-20.

Ward, N. A., Dixon, E., and Amsden, B. 2013. First report of impatiens downy mildew caused by Plasmopara obducens in Kentucky. Plant Dis. 97:428

Warfield, C. Y. 2012. Downy mildew of impatiens. GrowerTalks 75:78-86.

Warfield, C. Y., Blomquist, C. L., and Lovig, E. E. 2009. First report of downy mildew on nursery-grown Hellebore caused by Peronospora pulveracea in California. Plant Dis. 93:319.

Wegulo, S. N., Koike, S. T., Vilchez, M., and Santos, P. 2004. First report of downy mildew caused by Plasmopara obducens on impatiens in California. Plant Dis. 88:909.

Yu, S. X., Janssens, S. B., Zhu, X. Y., Lidén, M., Gao, T. G., and Wang, W. 2016 Phylogeny of Impatiens (Balsaminaceae): interpreting molecular and morphological evidence into a new classification. Cladistics 32:179-197. 